Invited Paper

\title{
Self-Compacting Concrete
}

\author{
Hajime Okamura ${ }^{1}$ and Masahiro Ouchi ${ }^{2}$
}

Received 14 November 2002, accepted 30 March 2003

\begin{abstract}
Self-compacting concrete was first developed in 1988 to achieve durable concrete structures. Since then, various investigations have been carried out and this type of concrete has been used in practical structures in Japan, mainly by large construction companies. Investigations for establishing a rational mix-design method and self-compactability testing methods have been carried out from the viewpoint of making selfcompacting concrete a standard concrete.
\end{abstract}

\section{Development of Self-Compacting Concrete}

For several years beginning in 1983 , the problem of the durability of concrete structures was a major topic of interest in Japan. The creation of durable concrete structures requires adequate compaction by skilled workers. However, the gradual reduction in the number of skilled workers in Japan's construction industry has led to a similar reduction in the quality of construction work. One solution for the achievement of durable concrete structures independent of the quality of construction work is the employment of self-compacting concrete, which can be compacted into every corner of a formwork, purely by means of its own weight and without the need for vibrating compaction (Fig. 1). The necessity of this type of concrete was proposed by Okamura in 1986. Studies to develop self-compacting concrete, including a fundamental study on the workability of concrete, have been carried out by Ozawa and Maekawa at the University of Tokyo (Ozawa 1989, Okamura 1993 \& Maekawa 1999).

The prototype of self-compacting concrete was first completed in 1988 using materials already on the market (Fig. 2). The prototype performed satisfactorily with regard to drying and hardening shrinkage, heat of hydration, denseness after hardening, and other properties. This concrete was named "High Performance Concrete" and was defined as follows at the three stages of concrete:

(1) Fresh: self-compactable

(2) Early age: avoidance of initial defects

(3) After hardening: protection against external factors

At almost the same time, "High Performance Concrete" was defined as a concrete with high durability due to a low water-cement ratio by Professor Aïtcin et

1Professor, Kochi University of Technology, Japan 2 Associate Professor, Kochi University of Technology, Japan. E-mail: ouchi.masahiro@kochi-tech.ac.jp al. (Gagne et al. 1989). Since then, the term high performance concrete has been used around the world to refer to high durability concrete. Therefore, the authors have changed the term for the proposed concrete to "Self-Compacting High Performance Concrete."

\section{Self-compactability of fresh concrete}

\subsection{Mechanism for achieving self-compactability}

The method for achieving self-compactability involves not only high deformability of paste or mortar, but also resistance to segregation between coarse aggregate and mortar when the concrete flows through the confined zone of reinforcing bars. Okamura and Ozawa have employed the following methods to achieve self-

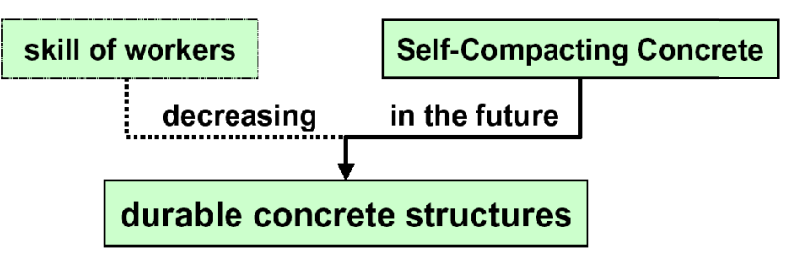

Fig. 1 Necessity for Self-Compacting Concrete.

Self-Compacting Concrete

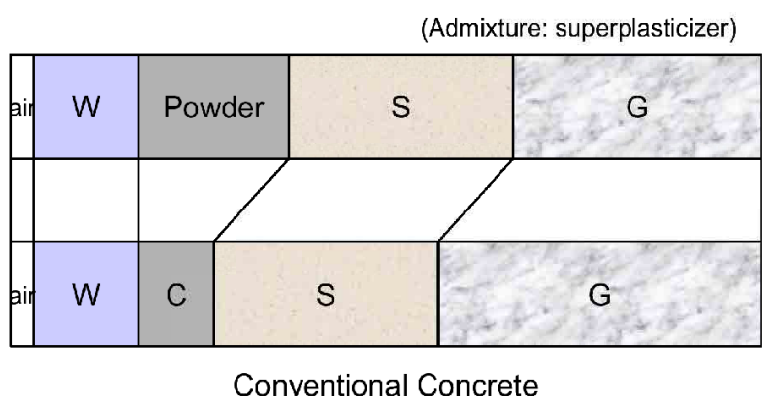

Fig. 2 Comparison of mix proportioning between SelfCompacting Concrete and conventional concrete. 


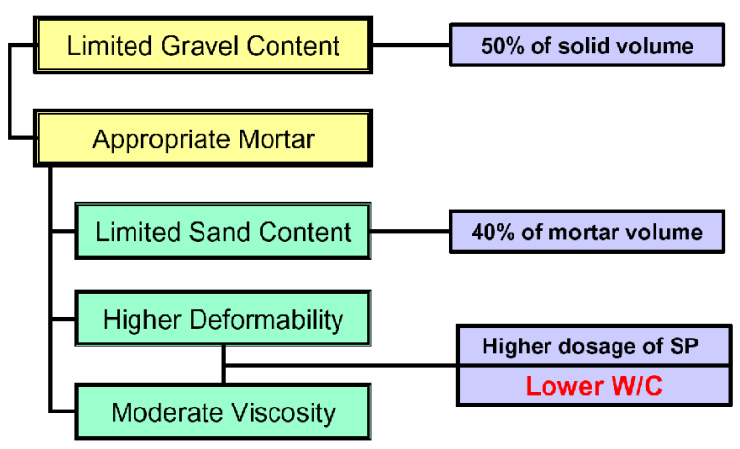

Fig. 3 Methods for achieving self-compactability.

compactability (Fig. 3) (1995):

(1) Limited aggregate content

(2) Low water-powder ratio

(3) Use of superplasticizer

The frequency of collision and contact between aggregate particles can increase as the relative distance between the particles decreases and then internal stress can increase when concrete is deformed, particularly near obstacles. Research has found that the energy required for flowing is consumed by the increased internal stress, resulting in blockage of aggregate particles. Limiting the coarse aggregate content, whose energy consumption is particularly intense, to a level lower than normal is effective in avoiding this kind of blockage.

Highly viscous paste is also required to avoid the blockage of coarse aggregate when concrete flows through obstacles (Fig. 4). When concrete is deformed, paste with a high viscosity also prevents localized increases in internal stress due to the approach of coarse aggregate particles. High deformability can be achieved only by the employment of a superplasticizer, keeping the water-powder ratio to a very low value.

The mix proportioning of self-compacting concrete is shown and compared with those of normal concrete and RCD (Roller Compacted concrete for Dams) concrete (Fig. 5). The aggregate content is smaller than conventional concrete that requires vibrating compaction. The

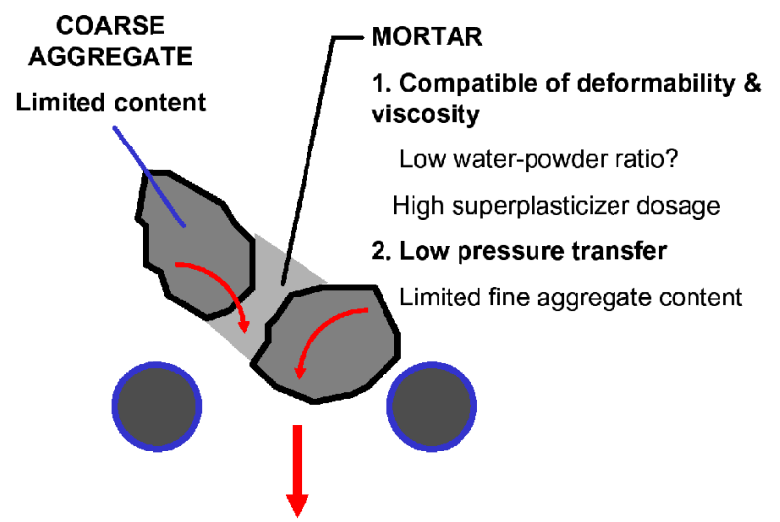

Fig. 4 Mechanism for achieving self-compactability.

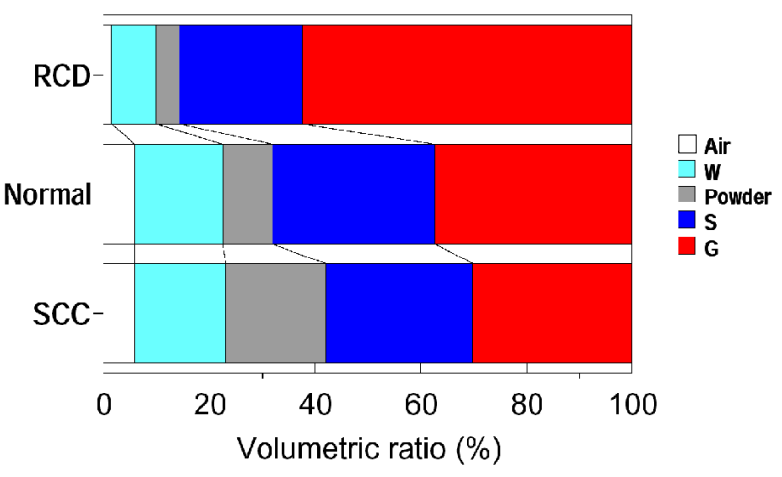

Fig. 5 Comparison of mix-proportioning of SCC with other types of conventional concrete.

ratios of the coarse aggregate volume to its solid volume $(G / G l i m)$ of each type of concrete are shown in Fig. 6. The degree of packing of coarse aggregate in SCC is approximately $50 \%$ to reduce the interaction between coarse aggregate particles when the concrete deforms. In addition, the ratios of fine aggregate volume to solid volume $(S / S l i m)$ in the mortar are shown in the same figure. The degree of packing of fine aggregate in SCC mortar is approximately $60 \%$ so that shear deformability when the concrete deforms may be limited. On the other hand, the viscosity of the paste in SCC is the highest among the various types of concrete due to its lowest water-powder ratio (Fig. 7). This characteristic is effective in inhibiting segregation.

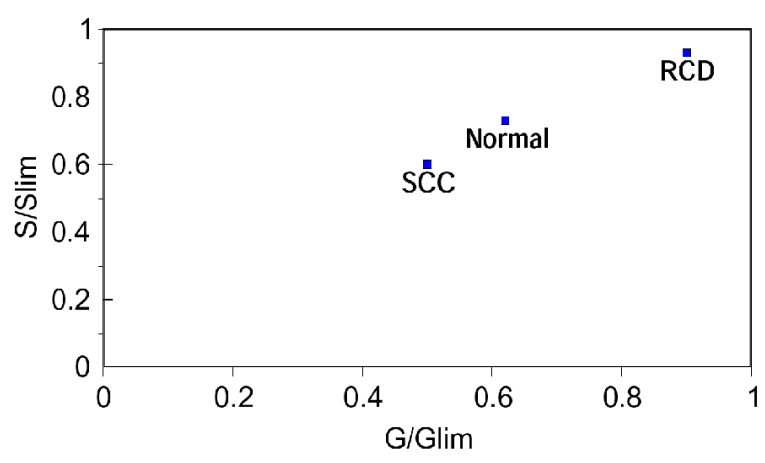

Fig. 6 Degree of aggregate's compaction-Coarse aggregate in concrete and fine aggregate in mortar.

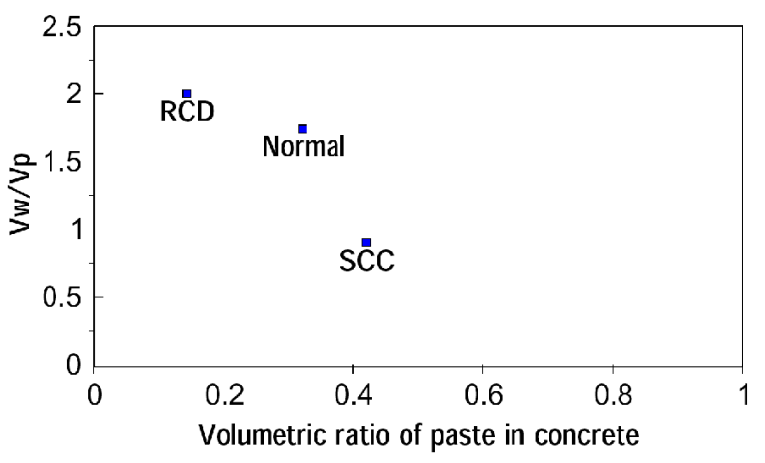

Fig. 7 Relationship between paste volume and waterpowder ratio. 


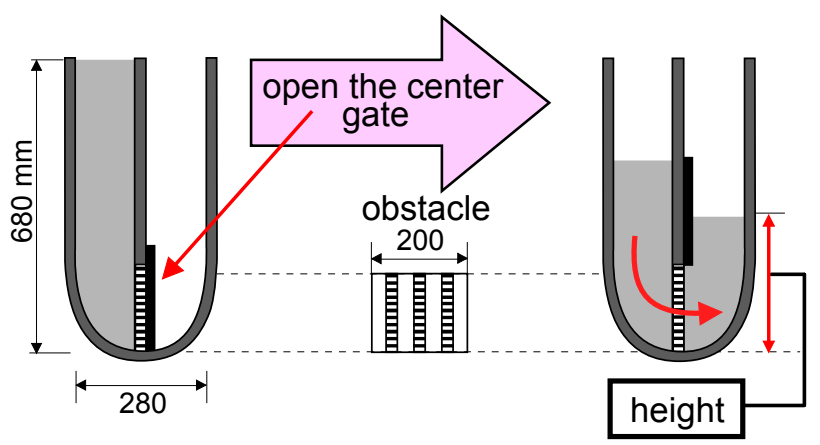

Fig. 8 U-flow test.

There are three purposes for self-compactability tests relating to practical purposes.

Test (1): To check whether or not the concrete is self-compactable for the structure

Test (2): To adjust the mix proportion when selfcompactability is not sufficient

Test (3): To characterize materials

As Test (1), the so-called U-flow test or Box test is recommended (Figs. 8, 9 and 10). The U-flow test was developed by the Taisei Group (Hayakawa 1993). In this test, the degree of compactability can be indicated by the height that the concrete reaches after flowing through an obstacle. Concrete with a filling height of over $300 \mathrm{~mm}$ can be judged as self-compacting. The Box-test is more suitable for detecting concrete with higher possibility of segregation between coarse aggregate and mortar.

If the concrete is judged to be having insufficient selfcompactability through test (1), the cause has to be detected quantitatively so that the mix proportion can be adjusted. Slump-flow and funnel tests (Fig. 11) have been proposed for testing deformability and viscosity, respectively, and the indices were also defined as $c$ and Rc.

$$
c=\left(S f l_{1} S f l_{2}-S f l_{0}^{2}\right) / S f l_{0}^{2},
$$

$S f l_{1}, S f l_{2}$ : measured flow diameter; $S f l_{0}$ : Slump cone diameter

$R_{c}=10 / t$,

$t$ (sec): measured time (sec) for concrete to flow through the funnel

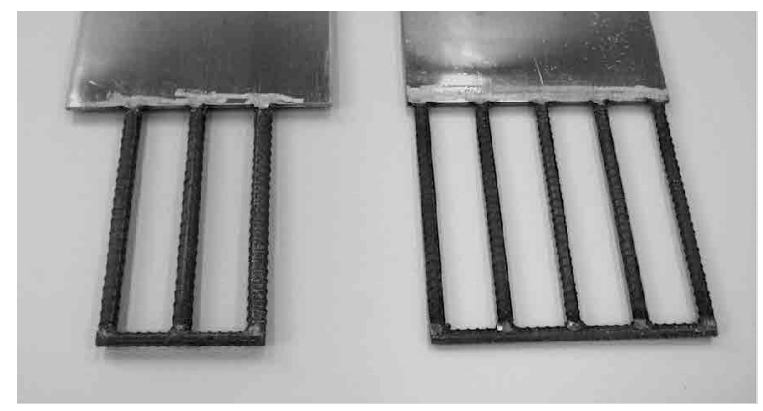

Fig. 10 Obstacles employed in Box test: R2 (Left) and R1 (Right).

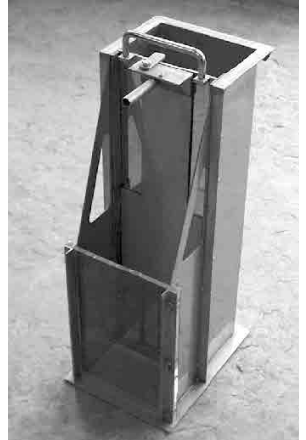

Fig. 9 Box test.

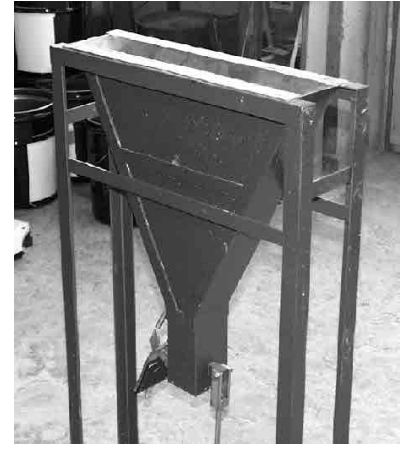

Fig. 11 V-funnel.
Flow and funnel tests for mortar or paste have been proposed to characterize materials used in selfcompacting concrete, e.g. powder material, sand, and super-plasticizer. Testing methods for the mortar properties were also proposed and the indices for deformability and viscosity were also defined as $m$ and $R m$ (Figs. 12 and 13).

$$
\begin{aligned}
& m=\left(d_{1} d_{2}-d_{0}^{2}\right) / d_{0}^{2}, \\
& d_{1}, d_{2}: \text { measured flow diameter; } \\
& d_{0}: \text { flow cone diameter } \\
& R m=10 / t \\
& t(\mathrm{sec}): \text { measured time }(\mathrm{sec}) \text { for mortar to flow } \\
& \text { through the funnel }
\end{aligned}
$$

A larger $m$ indicates higher deformability and a smaller $R m$ indicates higher viscosity. Characterizing methods for materials were proposed using the $m$ and $R m$ indices.

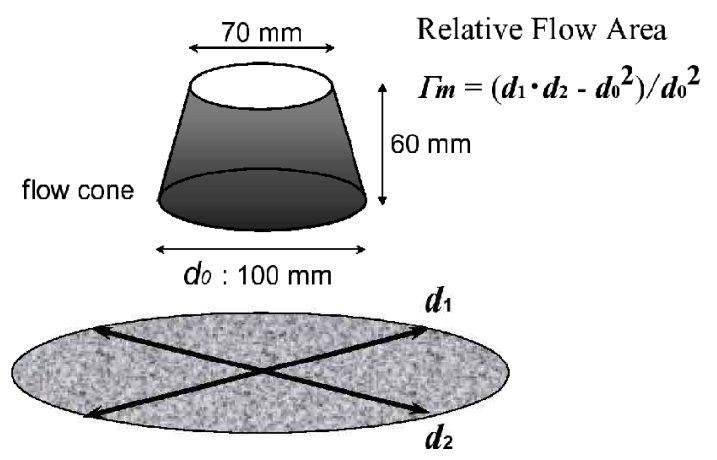

Fig. 12 Mortar flow test

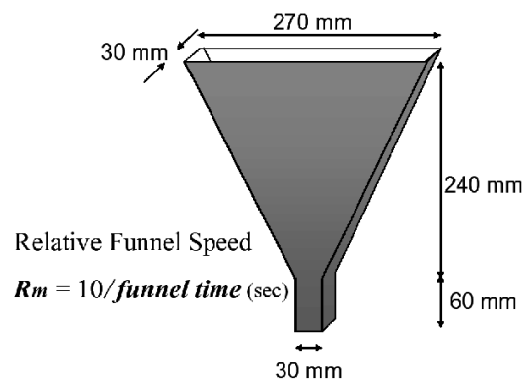

Fig. 13 Mortar funnel test. 


\subsection{Factors of self-compactability in terms of testing results}

The factors making up self-compactability were described in terms of the test results for fresh concrete and mortar below.

(1) Influence of coarse aggregate depending on spacing size

It is not always possible to predict the degree of compaction into a structure by using the test result on the degree of compaction of the concrete into another structure, since the maximum size of coarse aggregate is close to the minimum spacing between the reinforcing bars of the structure. For example, the relationship between coarse aggregate content in concrete and the filling height of the Box-type test, which the standard index for self-compactability of fresh concrete, is shown in Figs. 14 and 15. The relationship between the filling height through obstacle R1 and that through R2 varied depending on the coarse aggregate content. That test result shows that the influence of coarse aggregate on the flowability of fresh concrete largely depends on the size of the spacing of the obstacle. It can be said that the self-compactability of fresh concrete has to be discussed in terms of solid particles as well as in terms of liquid.

(2) Role of mortar as fluid in flowability of fresh concrete

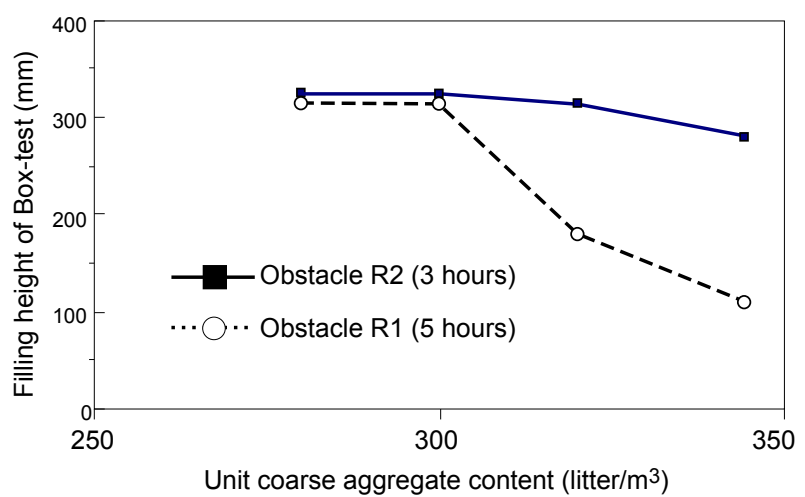

Fig. 14 Influence of coarse aggregate content on selfcompactability.

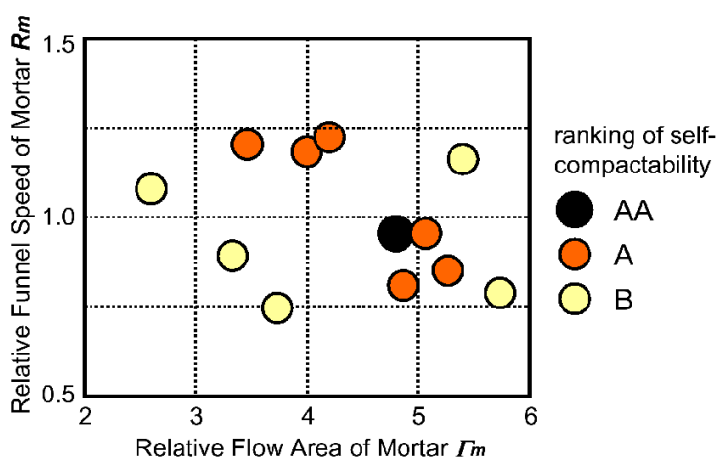

Fig. 15 Relationship between mortar's flowability and self-compctability of fresh concrete.
Sufficient deformability of the mortar phase in concrete is required so that concrete can be compacted into structures by its self-weight without need for vibrating compaction. In addition, moderate viscosity as well as deformability of the mortar phase is required so that the relative displacement between coarse aggregate particles in front of obstacles when concrete is to flow around such obstacles can be reduced and then segregation between coarse aggregate and mortar can be inhibited. The necessity for viscosity was confirmed by Hashimoto's visualization test.

The indices for mortar deformability $m$ and viscosity $R m$ were proposed by using mortar flow and funnel test results. The relationship between mortar deformability and viscosity and the self-compactability of fresh concrete is shown assuming a fixed coarse aggregate content (Fig. 15). The existence of an optimum combination of deformability and viscosity of mortar for achieving self-compactability of fresh concrete was demonstrated.

\section{(3) Role of mortar as solid particles}

In addition to its role as a liquid mentioned above, mortar also plays a role as solid particles. This property is so-called "pressure transferability", which can be apparent when the coarse aggregate particles approach each other and mortar in between coarse aggregate particles is subjected to normal stress (Fig. 16). The degree of the decrease in the shear deformability of the mortar largely depends on the physical characteristics of the solid particles in the mortar (Fig. 17) (Nagamoto 1997).

For example, the difference in the relationships between the funnel speeds of mortar and concrete due to

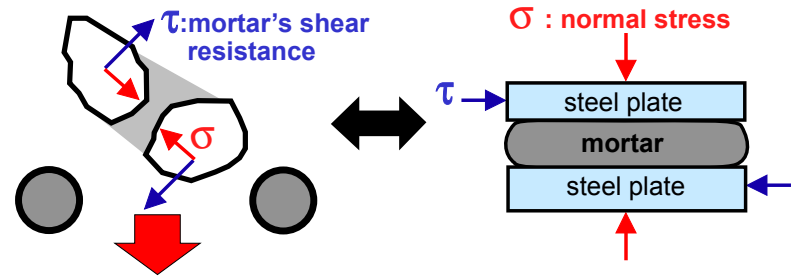

Fig. 16 Normal stress generated in mortar due to approaching coarse aggregate particles.
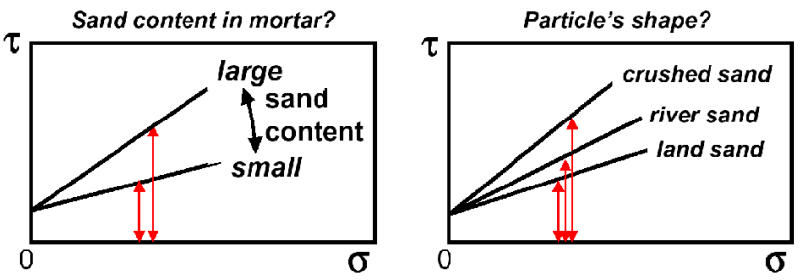

Fig. 17 Degree of increase in shear deform resistance due to depending on physical characteristics of solid particles. 


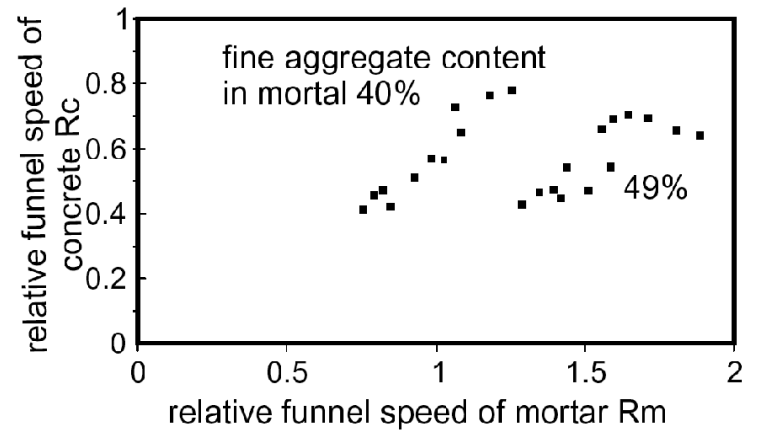

Fig. 18 Relationship between mortar's and concrete's flowability (V65 funnel).

differences in the fine aggregate content in mortar are shown in Fig. 18. It was found that the relationship between the flowability of mortar and concrete cannot always be unique due to differences in the characteristics of the solid particles in the mortar, even if the characteristics of the coarse aggregate and its content in concrete are constant.

A simple evaluation method for the stress transferability of mortar was proposed by using the ratio of the funnel speed of concrete with glass beads as the standard coarse aggregate $(R c s)$ to the speed of mortar $(R m)$ (Fig. 19) (Ouchi 2000). The higher stress transferability corresponds to the smaller value of $R c s / R m$. The relationships between fine aggregate content in mortar and

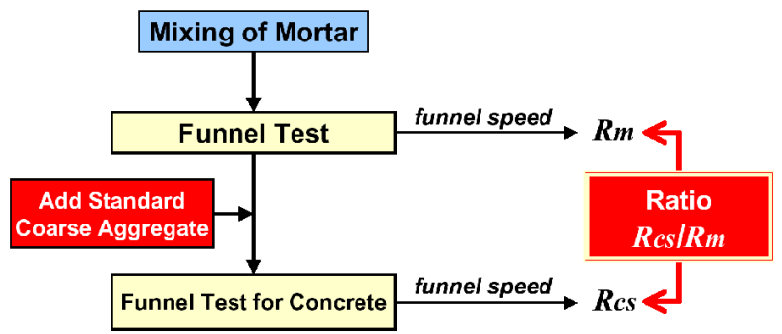

Fig. 19 A Simple Evaluation Method for Stress Transferability of Fresh Mortar.

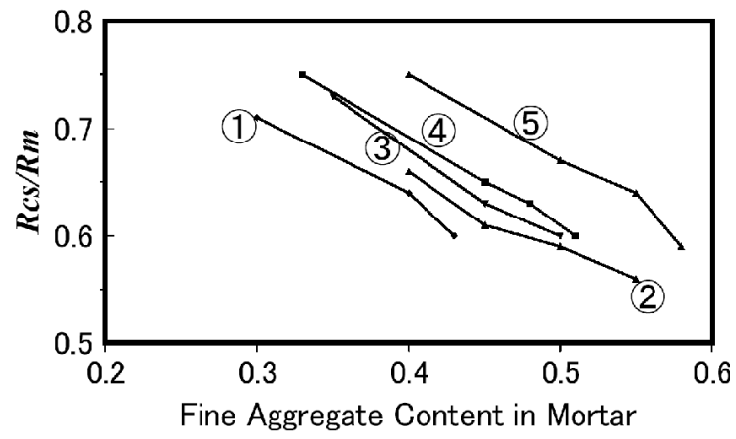

Fig. 20 Relationships between fine aggregate content in mortar and Rcs/Rm

[1: OPC+Crushed Sand(CS), 2: Fly Ash (FA)+CS, 3: FA+River Sand(RS), 4: OPC + RS, 5: OPC+Land Sand(LS)].

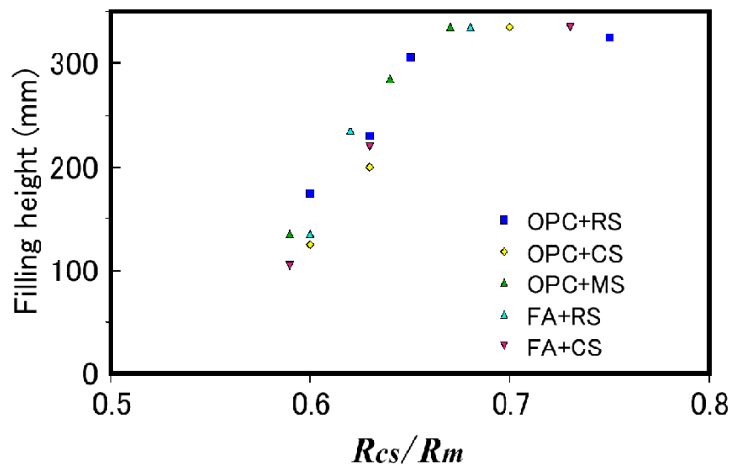

Fig. 21 Unique relationship between Rcs/Rm and degree of self-compactability.

$R c s / R m$ are shown in Fig. 20. The difference in the characteristics of the solid particles in mortar can be reflected by the value of $R c s / R m$. The relationship between $R c s / R m$ and the filling height of the Box-type test, which is the index for self-compactability of fresh concrete, is shown in Fig. 21. It was found that the relationship was unique despite the differences in the fine aggregate content in mortar or the characteristics of sand or powder particles.

(4) Influence of coarse aggregate -Content, shape and grading-

The influence of coarse aggregate on the selfcompactability of fresh concrete, especially flowability through obstacles, can be equal despite the shape of the coarse aggregate particles' shape as long as the ratio of coarse aggregate content to its solid volume in concrete is the same (Fig. 22) (Matsuo, et al., 1994). However, the influence of the grading of coarse aggregate has also to be considered if the spacing of the obstacles is very close to the maximum size coarse aggregate. For example, the relationships between the size of the concrete funnel's outlet and the flow speed through it depends on

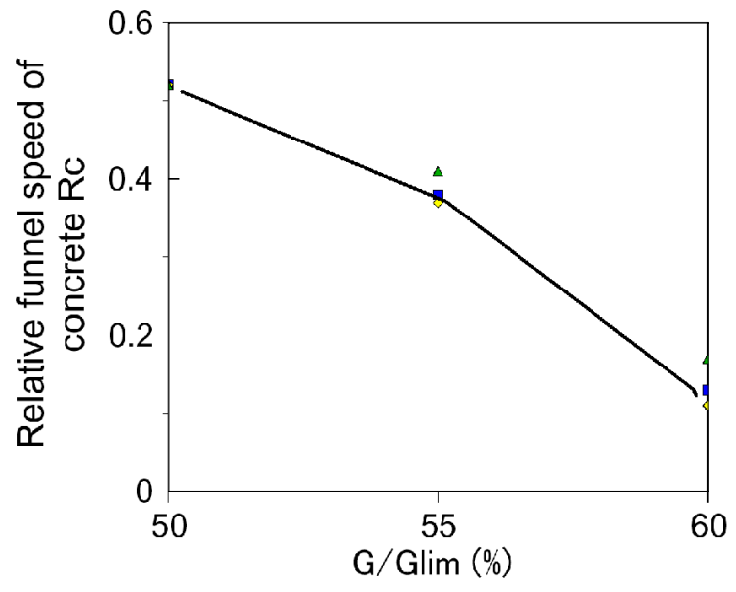

Fig. 22 Unique relationship between ratio of coarse aggregate content to its solid volume in concrete despite difference in gravel shape. 


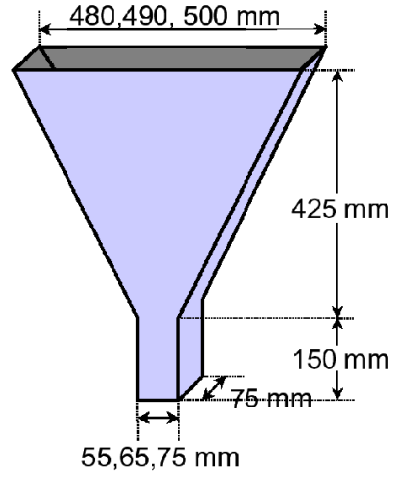

Fig. 23 V-funnel.

the fineness modulus of coarse aggregate FM even if the property of the mortar phase is the same (Figs. 23 and 24). It was found out that the flow speed of concrete through a funnel with an outlet width of $55 \mathrm{~mm}$ was largely influenced by the grading of the coarse aggregate.

\section{State of the art on Self-Compacting Con- crete}

\subsection{Current status of Self-Compacting Concrete} Self-compacting concrete has been used as a "special concrete" only in large general construction companies in Japan. In order for self-compacting concrete to be used as a standard concrete rather than a special one, new systems for its design, manufacturing and construction of self-compacting concrete need to be established. Various committee activities on self-compacting concrete have been carried out as a result.

Among them, a system by which the ready-mixed concrete industry can produce self-compacting concrete as a normal concrete would seem the most effective since, in Japan, as much as $70 \%$ of all concrete is produced by the ready-mixed concrete industry. Assuming a general supply from ready-mixed concrete plants,

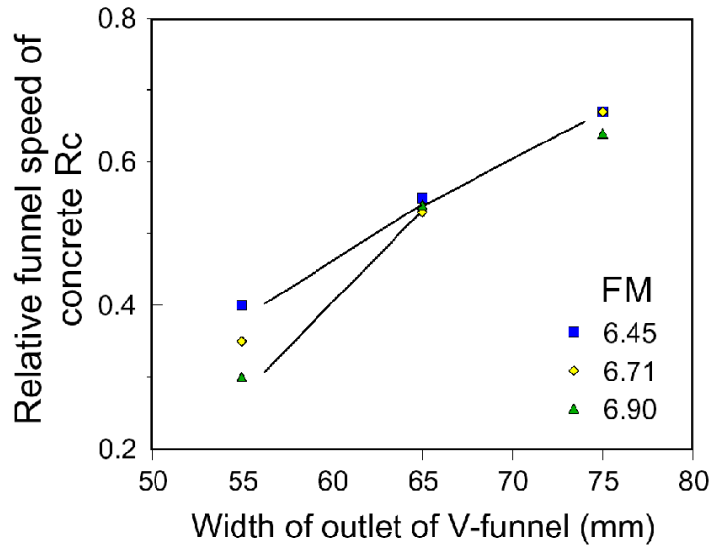

Fig. 24 Dominance of gravel grading for flowability through small spacing. investigations to establish the following items have been carried out mainly at the University of Tokyo since the development of the prototype.

(1) Self-compactability testing method

(2) Mix-design method

(3) Acceptance testing method at job site

(4) New type of powder or admixture suitable for self-compacting concrete

Of those items, (1) has already been mentioned in this paper. (2), (3) and (4) are described below

\subsection{Mix-design method}

(1) Rational mix-design method

Self-compactability can be largely affected by the characteristics of materials and the mix proportion. A rational mix-design method for self-compacting concrete using a variety of materials is necessary. Okamura and Ozawa (1995) have proposed a simple mix proportioning system assuming general supply from ready-mixed concrete plants. The coarse and fine aggregate contents are fixed so that self-compactability can be achieved easily by adjusting the water-powder ratio and superplasticizer dosage only.

(1) The coarse aggregate content in concrete is fixed at $50 \%$ of the solid volume.

(2) The fine aggregate content is fixed at $40 \%$ of the mortar volume.

(3) The water-powder ratio in volume is assumed as 0.9 to 1.0 , depending on the properties of the powder.

(4) The superplasticizer dosage and the final waterpowder ratio are determined so as to ensure selfcompactability.

In the mix proportioning of conventional concrete, the water-cement ratio is fixed at first from the viewpoint of obtaining the required strength. With self-compacting concrete, however, the water-powder ratio has to be decided taking into account self-compactability because self-compactability is very sensitive to this ratio. In most cases, the required strength does not govern the water-cement ratio because the water-powder ratio is small enough for obtaining the required strength for ordinary structures unless most of the powder materials in use is not reactive.

The mortar or paste in self-compacting concrete requires high viscosity as well as high deformability. This can be achieved by the employment of a superplasticizer, which results in a low water-powder ratio for high deformability.

(2) Adjustment of water-powder ratio and superplasticizer dosage

The characteristics of powder and superplasticizer largely affect the mortar property and so the proper waterpowder ratio and superplasticizer dosage cannot be fixed without trial mixing at this stage. Therefore, once 
the mix proportion is decided, self-compactability has to be tested by U-flow, slump-flow and funnel tests. Methods for judging whether the water-powder ratio or superplasticizer dosage are larger or smaller than the proper value by using the test results, and methods for estimating the proper values are necessary. The relationships between the properties of the mortar in selfcompacting concrete and the mix proportion have been investigated and then formulated. These formulae can be used to establish a rational method for adjusting the water-powder ratio and superplasticizer dosage to achieve appropriate deformability and viscosity (Ouchi 1998).

\subsection{Acceptance test at job site}

Since the degree of compaction in a structure mainly depends on the self-compactability of concrete, and poor self-compactability cannot be compensated by the construction work, self-compactability must be checked for the whole amount of concrete just before casting at the job site. However, conventional testing methods for self-compactability require sampling and this can be extremely laborious if the self-compactability acceptance test is to be carried out for the whole amount of concrete. A suitable acceptance test method for selfcompactability has been developed by Ouchi et al (1999).:

(1) The testing apparatus is installed between the agitator truck and the pump at the job site. The whole amount of concrete is poured into the apparatus.

(2) If the concrete flows through the apparatus, the concrete is considered as self-compactable for the structure. If the concrete is stopped by the apparatus, the concrete is considered as having insufficient selfcompactability and the mix proportion has to be adjusted.

This apparatus was successfully used at the construction site of the Osaka Gas LNG tank and saved a considerable amount of acceptance test work (Fig. 25) (Kitamura 1999).

\subsection{New type of superplasticizer suitable for Self-Compacting Concrete}

There is more room for improvement for admixtures such as superplasticizer suitable for self-compacting concrete. In order to achieve this purpose, characterization of materials is indispensable.

The requirements for superplasticizer in self-compacting concrete are summarized below.

(1) High dispersing effect for low water/powder (cement) ratio: less than approx. $100 \%$ by volume

(2) Maintenance of the dispersing effect for at least two hours after mixing

(3) Less sensitivity to temperature changes

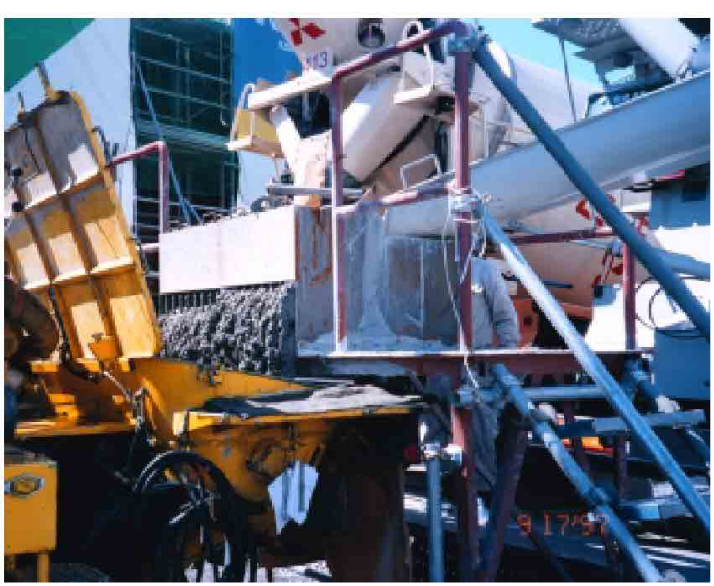

Fig. 25 Automatic acceptance test at job site.

There have been many examples of the development of new type of superplasticizer for self-compacting concrete. Characterization of the dispersing effect of superplasticizer independent of the effect of water flow is indispensable.

The authors found that the ratio of $m$ to $R m$ was almost constant with the variety of $V w / V p$ (volume ratio of water to powder) on condition that $S p / P$ was constant (Fig. 26). $\quad m / R m$, the ratio of $m$ to $R m$ was proposed as the index for the dispersing effect by superplasticizer (Fig. 27). The relationship between $S p / P$ and its effect $m / R m$ is quite different depending on the combination

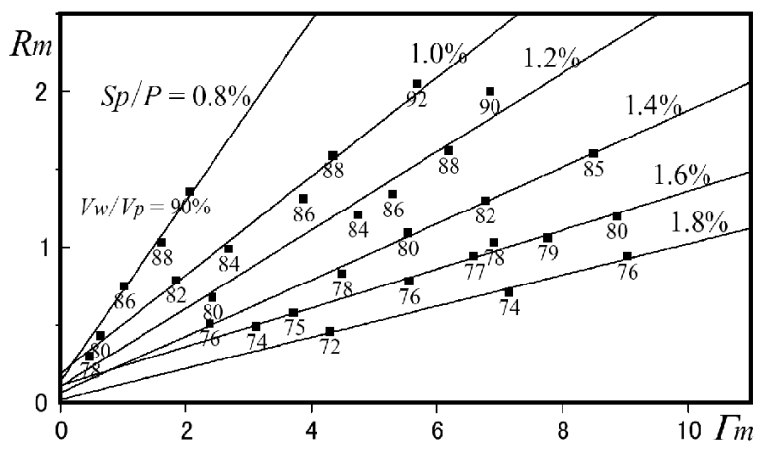

Fig. 26 Relationship between flow area and funnel speed of fresh mortar with variety of water-powder ratio and superplasticizer dosage.

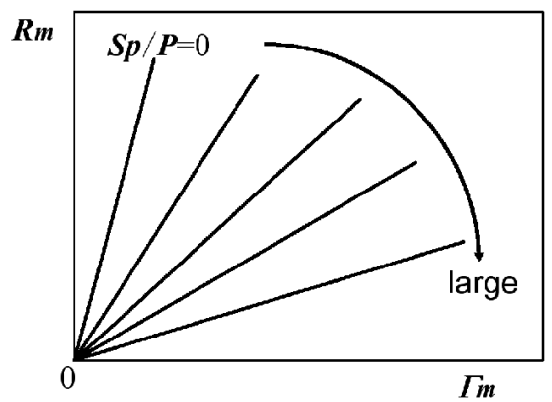

Fig. 27 Definition of dispersing effect by superplasticizer by using flow and funnel test results. 


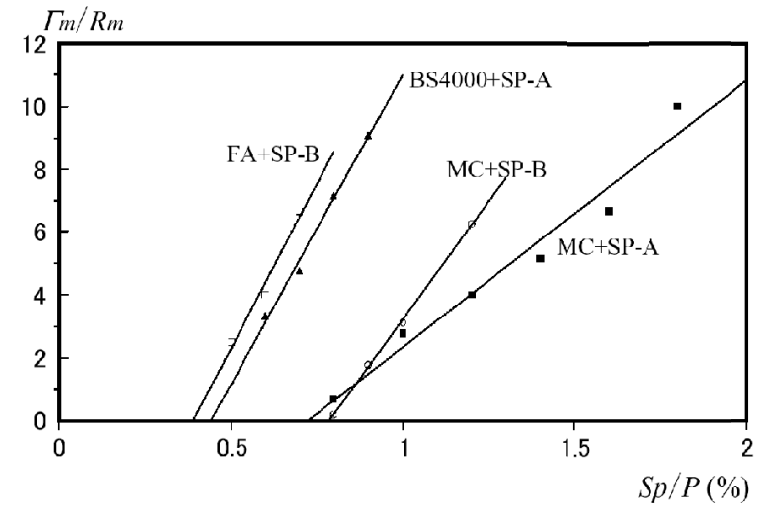

Fig. 28 Relationship between superplasticizer dosage and its effect in accordance with material in use.

of superplasticizer and powder material in use (Fig. 28) (Ouchi et al. 2001; Sugamata et al. 2001). At this stage, the relationship cannot be estimated without any experimental result due to the chemical effect of superplasticizer depending on the combination to the powder material in use.

\subsection{Segregation-inhibiting agent}

It has been found that it is possible to manufacture selfcompacting concrete with constant quality, especially self-compactability. However, any variation in material characteristics can affect self-compactability. The most influential variant is the water content of fine aggregate, which results in variations in the water content of the concrete itself. To solve this problem, some general construction companies employ a segregation-inhibiting agent. This type of agent is effective in making selfcompactability less sensitive to the variation of the water content in the concrete. Various agents are available for this purpose in Japan (Hibino 1998).

\section{Applications of Self-Compacting Concrete in Japan \\ 4.1 Current condition on application of self- compacting concrete in Japan}

After the development of the prototype of selfcompacting concrete at the University of Tokyo, intensive research was begun in many places, especially in the research institutes of large construction companies. As a result, self-compacting concrete has been used in many practical structures. The first application of selfcompacting concrete was in a building in June 1990. Self-compacting concrete was then used in the towers of a prestressed concrete cable-stayed bridge in 1991 (Fig. 29). Lightweight self-compacting concrete was used in the main girder of a cable-stayed bridge in 1992. Since then, the use of self-compacting concrete in actual structures has gradually increased. Currently, the main reasons for the employment of self-compacting concrete can be summarized as follows.

(1) To shorten construction period

(2) To assure compaction in the structure: especially

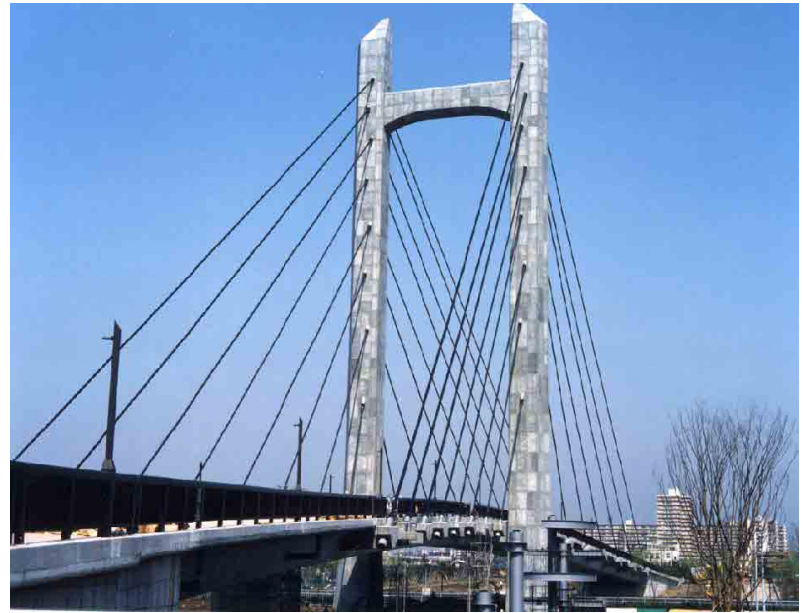

Fig. 29 Shin-kiba Ohashi bridge.

in confined zones where vibrating compaction is difficult

(3) To eliminate noise due to vibration: effective especially at concrete products plants

The volume of self-compacting concrete in Japan is shown in Fig. 30. The production of self-compacting concrete as a percentage of Japanese ready-mixed concrete, which accounts for $70 \%$ of total concrete production in Japan, is only $0.1 \%$. The current status of selfcompacting concrete is "special concrete" rather than "standard concrete."

Other applications of self-compacting concrete are summarized below.

Bridge (anchorage, arch, beam, girder, tower, pier, joint between beam \& girder)

Box culvert

Building

Concrete filled steel column

Tunnel (lining, immersed tunnel, fill of survey tunnel)

Dam (concrete around structure)

Concrete products (block, culvert, wall, water tank, slab, and segment)

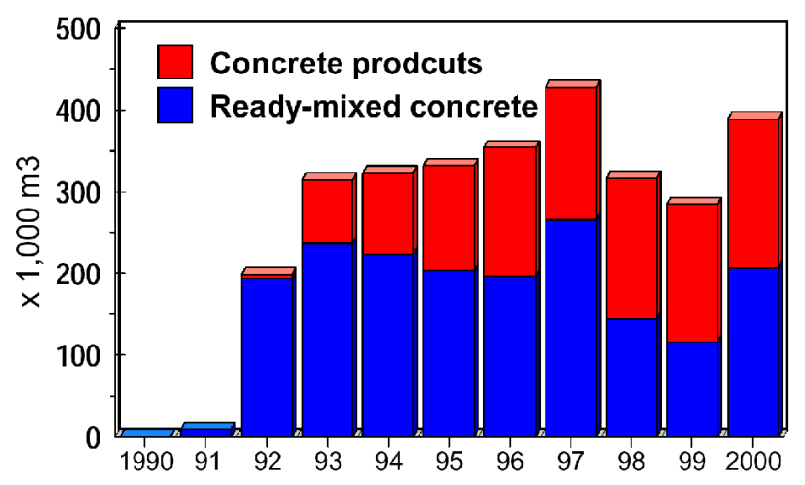

Fig. 30 Volume of SCC cast in Japan. 
Diaphragm wall

Tank (side wall, joint between side wall and slab)

Pipe roof

\subsection{Large scale construction}

Self-compacting concrete is currently being employed in various practical structures in order to shorten the construction period of large-scale constructions.

The anchorages of Akashi-Kaikyo (Akashi Straits) Bridge opened in April 1998, a suspension bridge with the longest span in the world (1,991 meters), is a typical example (Fig. 31) (Kashima 1999). Self-compacting concrete was used in the construction of the two anchorages of the bridge. A new construction system that makes full use of the performance of self-compacting concrete was introduced for this purpose. The concrete was mixed at the batcher plant next to the site, and was then pumped out of the plant. It was transported 200 meters through pipes to the casting site, where the pipes were arranged in rows 3 to 5 meters apart. The concrete was cast from gate valves located at 5-meter intervals along the pipes. These valves were automatically controlled so that the surface level of the cast concrete could be maintained. The maximum size of the coarse aggregate in the self-compacting concrete used at this site was $40 \mathrm{~mm}$. The concrete fell as much as 3 meters, but segregation did not occur, despite the large size of coarse aggregate. In the final analysis, the use of selfcompacting concrete shortened the anchorage construction period by $20 \%$, from 2.5 to 2 years.

Self-compacting concrete was used for the wall of a large LNG tank belonging to the Osaka Gas Company. The adoption of self-compacting concrete in this particular project had the following merits.

(1) The number of lots decreased from 14 to 10 as the height of one lot of concrete was increased.

(2) The number of concrete workers was reduced from 150 to 50 .

(3) The construction period of the structure decreased from 22 months to18 months.

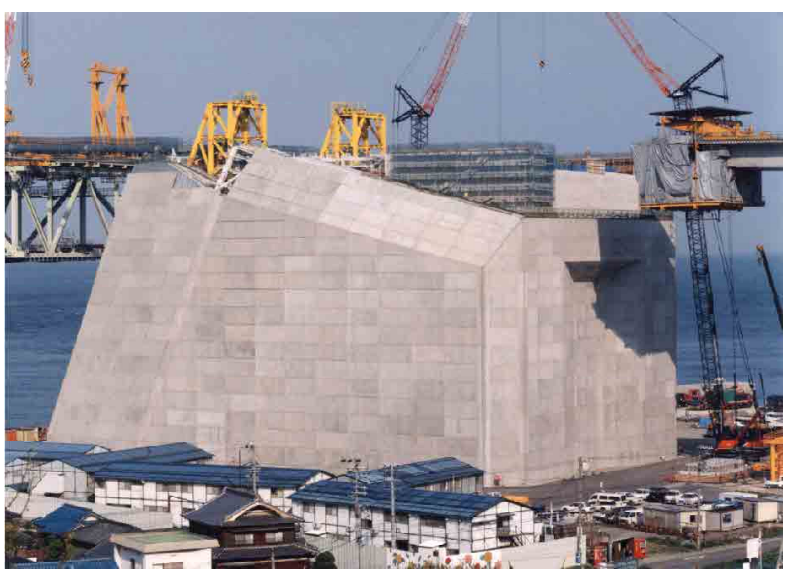

Fig. 31 Anchorage 4A of Akashi-Kaikyo bridge.
In addition, a rational acceptance test for selfcompactability at the job site was newly introduced. The concrete casting was completed in June 1998.

\subsection{Concrete products}

Self-compacting concrete is often employed in concrete products to eliminate vibration noise (Fig. 32). This improves the working environment at plants and makes the location of concrete products plants in urban areas possible. In addition, the use of self-compacting concrete extends the lifetime of mould for concrete products (Uno 1999). The production of concrete products using self-compacting concrete has been gradually increasing (Fig. 33).

\subsection{Necessity for new structural design and construction systems}

Using self-compacting concrete saves the cost of vibrating compaction and ensures the compaction of the concrete in the structure. However, total construction cost cannot always be reduced, except in large-scale constructions. This is because conventional construction systems are essentially designed based on the assumption that vibrating compaction of concrete is necessary.

Self-compacting concrete can greatly improve construction systems previously based on conventional

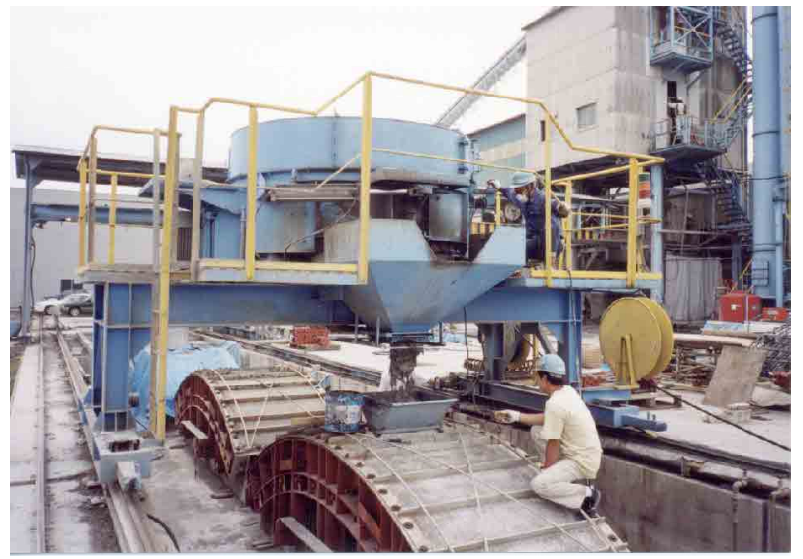

Fig. 32 Casting of SCC for Tunnel Segment.

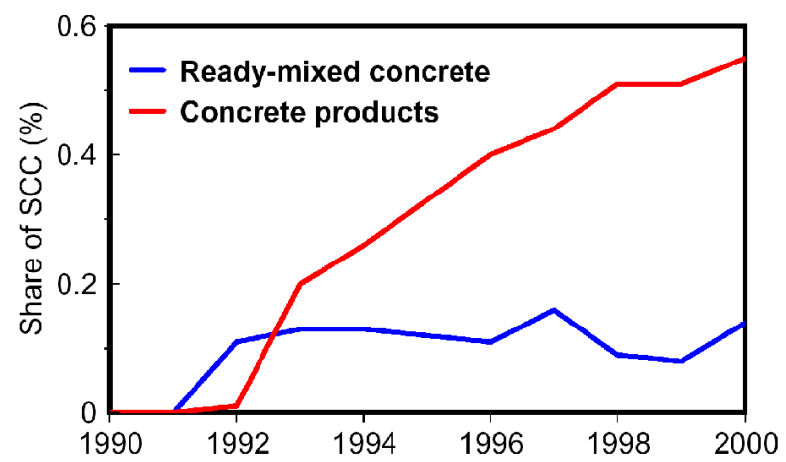

Fig. 33 Volume of SCC for concrete products in Japan. 


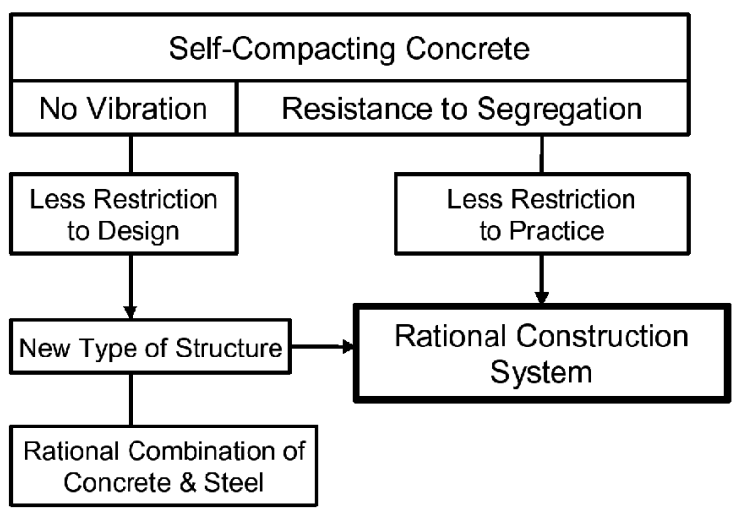

Fig. 34 New construction system achieved by making full use of SCC (Proposed by Ozawa).

concrete that required vibrating compaction. This sort of compaction, which can easily cause segregation, has been an obstacle to the rationalization of construction work. Once this obstacle is eliminated, concrete construction can be rationalized and a new construction system, including formwork, reinforcement, support and structural design, can be developed (Fig. 34).

One example of this is the so-called sandwichstructure, where concrete is filled into a steel shell. Such a structure has already been completed in Kobe, and could not have been achieved without the development of self-compacting concrete (Fig. 35) (Shishido et al. 1999).

\section{Conclusions}

Since a rational mix-design method and an appropriate acceptance testing method at the job site have both largely been established for self-compacting concrete, the main obstacles for the wide use of self-compacting concrete can be considered to have been solved. The next task is to promote the rapid diffusion of the techniques for the production of self-compacting concrete and its use in construction. Rational training and qualification systems for engineers should also be estab-

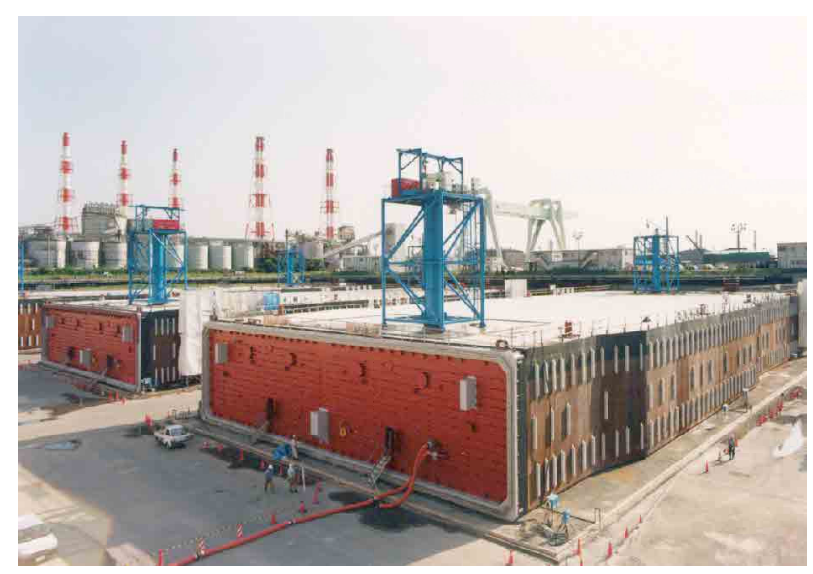

Fig. 35 Sandwich structure for immersed tunnel. lished. In addition, new structural design and construction systems making full use of self-compacting concrete should be introduced.

When self-compacting concrete becomes so widely used that it is seen as the "standard concrete" rather than a "special concrete," we will have succeeded in creating durable and reliable concrete structures that require very little maintenance work.

\section{References}

Gagne, R., Pigeon, M., and Aïtcin, P. C. (1989). "Deicer salt scaling resistance of high performance concrete." Paul Klieger Symposium on Performance of Concrete, SP-122, ACI.

Hayakawa, M., Matsuoka, Y., and Shindoh, T. (1993). "Development \& application of super workable concrete." RILEM International Workshop on Special Concretes: Workability and Mixing.

Hibino, M., Okuma, M., and Ozawa, K. (1998). "Role of viscosity agent in self-compactability of fresh concrete." Proceedings of the Sixth East-Asia Conference on Structural Engineering \& Construction, 2, 1313-1318.

Kashima, S., Kanazawa, K., Okada, R., and Yoshikawa, S. (1999). "Application of self-compacting concrete made with low-heat cement for bridge substructures of Honshu-Shikoku Bridge Authority." Proceedings of the International Workshop on Self-Compacting Concrete, 255-261.

Kitamura, H., Nishizaki, T., Ito, H., Chikamatsu, R., Kamada, F., and Okudate, M. (1999). "Construction of prestressed concrete outer tank for LNG storage using high-strength self-compacting concrete." Proceedings of the International Workshop on SelfCompacting Concrete, 262-291.

Maekawa, K., and Ozawa, K. (1999). "Development of SCC's prototype." (written in Japanese), SelfCompacting High-Performance Concrete, Social System Institute, 20-32.

Nagamoto, N., and Ozawa, K. (1997). "Mixture proportions of self-compacting high performance concrete," ACI International, SP-172, 623-636.

Okamura, H., Maekawa, K., and Ozawa, K. (1993). "High Performance Concrete." Gihodo Publishing.

Okamura, H. and Ozawa, K. (1995). "Mix-design for self-compacting concrete." Concrete Library of JSCE, 25, 107-120.

Ouchi, M., Hibino, M., Ozawa, K.. and Okamura, H. (1998). "A rational mix-design method for mortar in self-compacting concrete." Proceedings of the Sixth East Asia-Pacific Conference on Structural Engineering \& Construction, 2, 1307-1312.

Ouchi, M. (1999). "State-of-the-art report on selfcompactability evaluation." Proceedings of the International Workshop on Self-Compacting Concrete (CD-ROM). Also available from Concrete Engineering Series, 30, JSCE.

Ouchi, M. and Edamatsu, Y. (2000). "A Simple evaluation method for interaction between coarse aggregate 
and mortar particles in self-compacting concrete." Transaction of JCI.

Ouchi, M., Hibino, M., Sugamata, T., and Okamura, H. (2001). "A quantitative evaluation method for the effect of superplasticizer in self-compacting concrete", Transactions of JCI, 15-20.

Ozawa, K., Maekawa, K., Kunishima, M., and Okamura, H. (1989). "Development of high performance concrete based on the durability design of concrete structures", Proceedings of the second EastAsia and Pacific Conference on Structural Engineering and Construction (EASEC-2), 1, 445-450.

Shishido, T., Shiraiwa, S., Ishii, J., Yamamoto, S., and
Kume, H. (1999). "Pouring works of high fluidity concrete for immersed tunnel by steel-concrete composite structure." Proceedings of the International Workshop on Self-Compacting Concrete, 328-346.

Sugamata, T., Hibino, M., Ouchi, M., and Okamura, H. (2001). "Effects of molecular structures of polycarboxylate polymers on cement particles dispersibility." Concrete Library International, 38, JSCE.

Uno, Y. (1999). "State-of-the art report on concrete products made of SCC," Proceedings of the International Workshop on Self-Compacting Concrete, 262291. 